\title{
The Value of Land Use Patterns and Preservation Policies
}

by

\author{
Martin D. Heintzelman
}

\author{
A thesis submitted \\ in partial fulfillment of the requirements \\ for the degree of \\ Master of Science \\ (Natural Resources and Environment) \\ in The University of Michigan \\ April, 2010
}

Thesis Committee:

Professor Michael R. Moore, Chair

Professor Steven L. Yaffee 



\section{Abstract}

In many communities, land-use and open-space preservation have become important concerns. Using a large dataset containing every home sale in the state of Massachusetts over 8 years, this paper simultaneously measures the impact of the mix of land-uses in the immediate neighborhood of a home on property values and the impact of a locallyimplemented program, the Community Preservation Act (CPA), which provides funds for local open-space and historic preservation as well as affordable housing. I exploit the panel nature of the dataset to conduct a difference-in-differences analysis using local as well as house level fixed effects to overcome omitted variables bias. My results indicate that, on average, passage of the CPA reduces property values by about 1.5\% in Massachusetts towns. However, when I allow the CPA effect to differ by county, I find some heterogeneity - it increases property values in some communities and reduces them in others. Variation in local spending priorities appears to have little impact on property values or the effect of the CPA. Finally, I find that cropland and pasture, as well as low-density residential development, are the most preferred local land-uses, and that homes are more expensive as one increases distance to highways and active rail lines. 


\section{Acknowledgements}

Thanks go to Michael R. Moore for constant advice and support throught the process of writing this thesis. Financial support was provided by the David P. Mans and Patricia Z. Spector Scholarship and Clarkson University. I would also like to thank seminar participants at Clarkson University, the NAREA 2009 Annual Meeting in Burlington, VT, and the 2009 WEAI Annual Meeting in Vancouver for useful thoughts and feedback. I would also like to acknowledge the research assistance of Patrick Becker, Peter Claus-Landi, Dustin Greszkowiak, and Kristina Pierce. All errors are my own. 


\section{Contents}

1 Introduction 1

2 Policy Background 4

3 Data and Empirical Strategy $\quad 8$

4 Results 13

5 Discussion $\quad 22$

6 Conclusions $\quad 26$ 


\section{Introduction}

Beyond the basic characteristics of a home such as its size and the size of the property upon which it sits, within a given real estate market, much of a home's value derives from the amenities provided by its location. These locational factors include convenience (distance to places of employment, shopping, highways, rail stations), amenities (local land-uses, open-space, parks), disamenities (distance to waste facilities, rail-lines, industrial zones), as well as regulatory impacts (zoning, historic districts). Policy-makers have long tried to impact property values through zoning and city/town/urban planning, as well as explicit policies to preserve/protect open-space, farmland, and wildlife habitat. This paper uses a fixed-effects, differences-in-differences, approach to examine the impacts of local land uses, zoning rules, and other locational factors on property values, as well as those of policies designed to preserve open-space and historic sites, and simultaneously provide for affordable housing. It focuses on the state of Massachusetts and that state's Community Preservation Act $(\mathrm{CPA})$.

Briefly, the CPA is a policy enacted at the town level that allows towns to leverage a property tax surcharge with state matching funds for the purposes of Open Space Preservation, Historic Preservation, and Community Housing. The policy, in place since 2001, has been enacted slowly over time by towns, so that, to date, 142 towns out of a possible 351 have enacted the CPA, and these enactments have been spread over 9 years, 2001-2009. In fact, some towns are just now taking up the measure. One of the aims of this paper is to study the ex post impacts of CPA passage on property values.

Of course, while this paper is focusing on one state and one particular policy, this is hardly an issue that is isolated to Massachusetts. Since 1988, some 1,686 conservation measures have been approved by voters in at least 43 states out of 2,233 total measures on ballots. Altogether, these measures have set aside some $\$ 53$ Billion for conservation. ${ }^{1}$ Massachusetts is also not the only state to have a matching funds program. New Jersey's Green Acres Program is just one other example of a similar policy that provides state aide

\footnotetext{
${ }^{1}$ Data from the LandVote database maintained by the Trust for Public Land, http://www.tpl.org/
} 
to local communities seeking to preserve open space.

An extensive literature on the economic values of varying land-uses exists, mostly focusing on the value of open-space, variously defined. ${ }^{2}$ This literature consistently finds that open-space in its many guises, including cropland, pasture, forest, and urban parks, is positively related to property values. What is less consistent is the magnitude of this effect. Empirical estimates of the impact of open-space vary considerably both between studies and even in different areas within the same study (Heintzelman, 2010). Most often, this literature has used cross-sectional data to explore the value of open space, and is thus susceptible to omitted variables bias. A critical contribution of this piece is to use a 'panel' like dataset enabling me use a fixed-effects analysis that greatly reduces the range of possible omitted variables.

The literature on voter referenda for open-space preservation is considerably less deep. Kotchen and Powers (2006) and Nelson et. al. (2007) analyze what drives the appearance and success of these referenda in states and local communities. They find that preservation is a normal good - wealthier communities are more likely to vote for preservation. Kotchen and Powers (2006) also find that preservation is most likely in suburban, rather than urban or rural, communities where development pressure is perceived to be highest. Only Heintzelman (2010) has previously studied the impacts of these referenda, and a small sample size prevents him from drawing firm conclusions about the impacts.

My results indicate that, on average, passage of the CPA reduces property values by about $1.5 \%$ in Massachusetts towns. However, when I allow the CPA effect to differ by county, I find some heterogeneity - it increases property values in some communities and reduces them in others. Limited evidence exists on the extent to which different local spending priorities impact the overall effect. I also find that cropland and pasture, as well as low-density residential development, are the most preferred local land-uses, and that homes are more expensive as one increases distance to highways and active rail lines.

Section 2 provides a detailed background information on the Community Preservation

\footnotetext{
${ }^{2}$ See McConnell and Walls (2005) for a survey or Waltert and Schlapfer (2007) for a meta-analysis of this literature. For more recent contributions see Heintzelman (2010) and Kuminoff (2008), amongst others.
} 
Act. Section 3 describes the research methodology. Section 4 provides the results, Section 5 interprets and extends the basic results, and Section 6 concludes. 


\section{Policy Background}

The Massachusetts Community Preservation Act was passed in 2000. It is a state program that provides matching funds to those towns who choose, through a referendum, to enact property tax surcharges of up to $3 \%$ and spend the additional funds, both those raised through the surcharge and the matching funds, on open-space preservation, historic preservation, and 'community' (affordable) housing. In practice, money has also been spent to provide recreational facilities. ${ }^{3}$ Towns are required to spend at least $10 \%$ of funds raised on each of the three core areas, and are free to allocate the remaining $70 \%$ as they wish. In general, towns appoint a Community Preservation Committee to recommend projects to be funded, and final decisions must be approved by the town meeting. The funds are held in separate from general town accounts and are not available to address other local spending priorities. The tax surcharge may include any or all of three tax exemptions: for low income households, for the first $\$ 100,000$ of property value, and for commercial and industrial properties. Finally, the adoption process is a two-stage process: first, the language of the referendum and parameters of the policy, the surcharge rate and possible exemptions, are approved either through the town meeting or through a petition drive; second, the referendum must be approved in a referendum vote.

As of June 2009, 142 communities have adopted the CPA out of the 351 towns and cities in Massachusetts. In addition to these communities, some 58 communities have rejected the CPA at the referendum stage. ${ }^{4}$ Figure 2 shows a map of the towns and cities of Massachusetts by whether they have passed or rejected the CPA. Figure 2 shows a map of enacting communities color - coded by the date of adoption. According the Community Preservation Coalition, an organization that advocates for communities to adopt the CPA, "Using CPA funds, municipalities have preserved 10,274 acres of open space, including important wetland resources such as lakes, rivers, and saltwater ponds. In the area of affordable housing, CPA funds have allowed for the creation or rehabilitation of more

\footnotetext{
${ }^{3}$ From $2001-2007$, the state matched locally raised funds at a rate of $100 \%$. In 2008 , this fell to $67 \%$ and may be as low as $35 \%$ in 2009 . The state matching funds come from a fee charged for deed transactions in the state.

${ }^{4} 19$ Communities initially rejected the CPA and then later enacted it.
} 


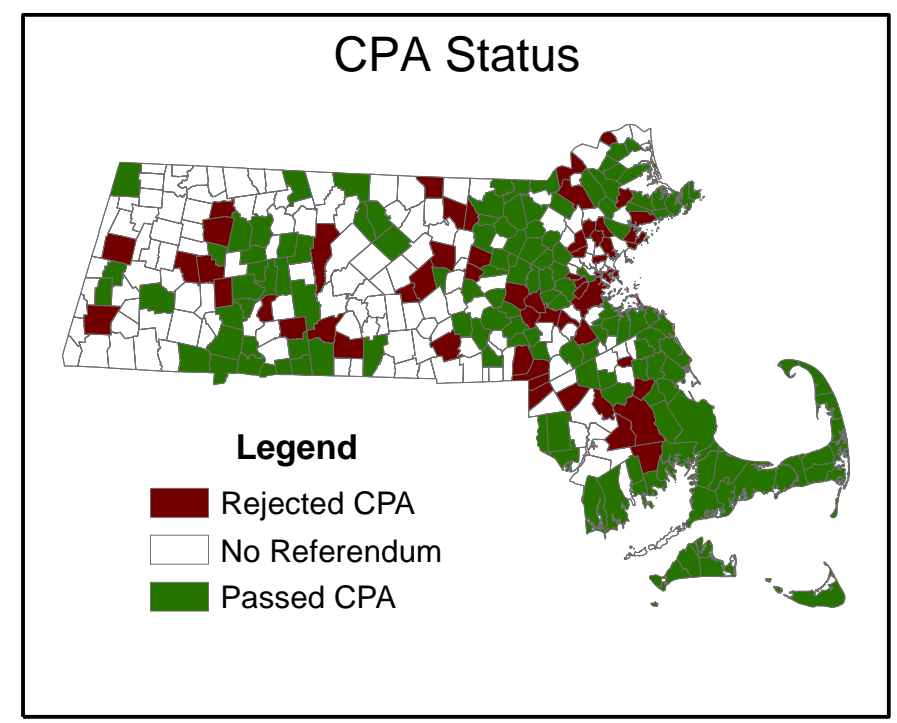

Figure 1: CPA Status

than 2,300 affordable housing units and the development of hundreds of innovative affordable housing programs. Finally, more than 1,300 appropriations for historic preservation projects and over 500 recreation projects have been approved under the program." 5 Of those communities that have passed the CPA, $52 \%$ choose the highest potential surcharge rate of $3 \%$. The average surcharge rate is $2.227 \%$. $75.35 \%$ of enacting towns exempted low income households and nearly $79 \%$ exempted the first $\$ 100,000$ in home value. Only $3.5 \%$ of towns exempted commercial and industrial property. No communities that have ever passed the CPA have subsequently withdrawn from the program, and three towns have, subsequent to initial passage, passed a second referendum to increase the surcharge rate. According to preliminary data from the Massachusetts Department of Revenue (DOR), quite a bit of variation exists in how the CPA money that has been raised so far has been spent. On average, towns have spent about $35 \%$ of CPA funds on Open Space, $22 \%$ on Affordable Housing, $13.2 \%$ on recreation, and $29.8 \%$ on Historic Preservation. ${ }^{6}$

\footnotetext{
5 "Summary of an Act to Sustain Community Preservation, SB 90", available at http://www.communitypreservation.org/CPALegislation.cfm.

${ }^{6}$ To give an idea of the degree of variation in spending patterns, the standard deviations of these shares, respectively and in terms of percentage points, are $28 \%, 24 \%, 17 \%$, and $26 \%$.
} 


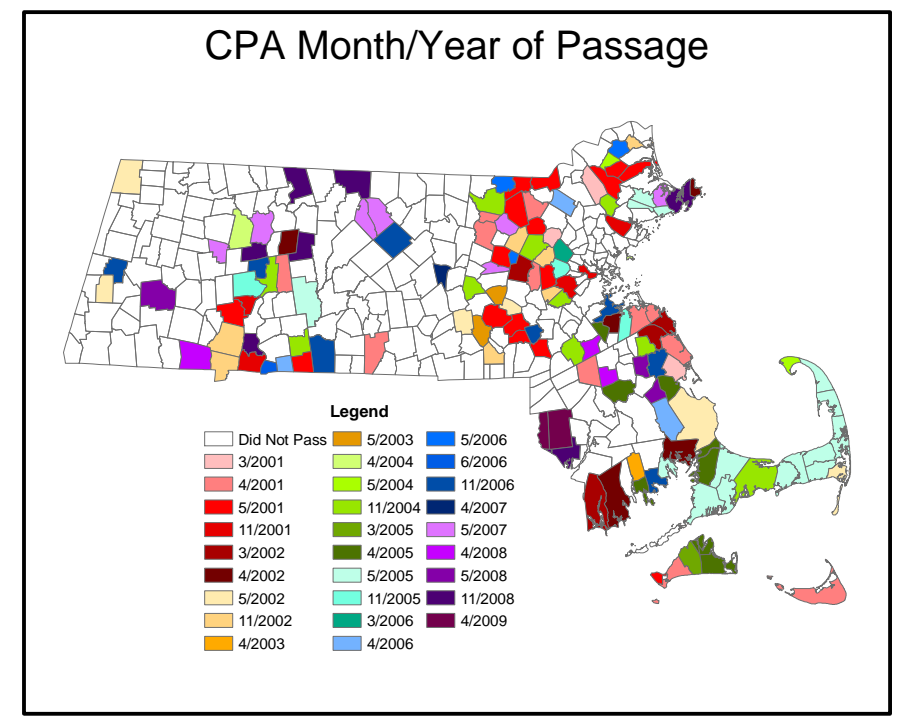

Figure 2: Month/Year of CPA Passage

Intuitively, it is not clear what impact the CPA should have on property values as a number of possible effects are acting simultaneously. A first thought is that towns are opting into the program, so presumably a majority of voters in the enacting towns think that, on average, the policy will be good for their town, and in turn, would be good for property values. For one thing, through the matching funds, towns are essentially able to purchase public goods at a reduced price - provided that all of the outcomes of the CPA are, in fact, public goods. Basic consumer theory tells us that consumers, or, in this case, towns, cannot be made worse off by a decrease in prices. However, many voters may have other reasons to vote for the CPA, regardless of the impact on property values. For instance, renters, or those meeting surcharge exemptions, if in place, stand only to gain from the CPA as they receive additional public goods at no additional cost. This implies that a passing vote does not necessarily imply expectations of average improvements in social welfare. Ignoring the political economy aspects of the problem, it is still not clear what the impact of the CPA should be. It simultaneously includes both an increase in taxes and an increase in goods provision. Following Brueckner (1982), average property 
values will be highest when the level of public goods provision is optimal. So, if the CPA is moving towns towards the optimum it will increase property values, but if it is pushing them beyond the optimum it will lower property values. In addition, while the tax-cost of the CPA is clear up front - consumers presumably have a very good idea of what the surcharge will imply about their annual tax burden, the benefits of the program, particularly at the time of the vote, are unclear. Much of the money being raised is simply being set aside for future purchases, and towns have no ex-ante obligation to publicize the expected uses of the money. This implies that consumers, in purchasing homes, may be very aware of the taxes they are paying, but less aware about the benefits being provided. The CPA also has supply effects. Restrictions on development restrict the supply of housing, which should increase property values. However, the provisions for affordable housing may undercut these effects by providing for additional high-density residential development, which both increases supply of housing and provides a public 'bad' in the sense that high density residential housing generally reduces property values. 


\section{$3 \quad$ Data and Empirical Strategy}

I employ a standard hedonic regression analysis to estimate the effects of land-use characteristics and CPA passage on residential transaction prices. I have data on all residential property sales in the state of Massachusetts for the years 2000-2007. This dataset include the sales price, date, and location of the home as well as a number of structural characteristics including lot size, interior size, bedrooms, bathrooms, and some indication of the 'style' of the home. I use GIS to attach geographical information such as land-uses, zoning information, distance to highways, rail lines, and rail stations to the home sales data. ${ }^{7}$ In addition, I include monthly, town-level, unemployment rate data from the Massachusetts Department of Revenue (DOR). Finally, I include town-level data on the CPA including the date of passage, the surcharge rate, and included exemptions, as well as preliminary information on CPA expenditures, also from the DOR. After accounting for erroneous observations and those missing critical pieces of information (most often the date of a home's construction), I am left with 623,163 observations. $^{8}$

This paper, in a sense, is doing double duty by estimating traditional hedonic effects in addition to the treatment effect of the policy, and to estimate both successfully, I must overcome some econometric obstacles. A major issue in estimating hedonic models, generally, is the problem of omitted variables (Parmeter and Pope, 2009). That is the common problem in any regression analysis whereby, if an unobserved variable is correlated with both the dependent and one more included independent variables, the estimates of the effects of the included variables will be biased. An uncountably high number of factors go into the value of a home, and many of these factors are unobservable to the researcher. So, if follows that if any of these unobservables are correlated with any of the included characteristics, ones estimates will be biased. Similarly, in estimating treatment effects, selection bias may be a problem if the outcome variable, which is, in this case, property values, is correlated with a factor that, in turn, is correlated with an observation receiving the treatment (Greenstone

\footnotetext{
${ }^{7}$ Unfortunately, most of the GIS data is not longitudinal in nature, but is instead a snapshot of a particular time, which varies by variable. The land-use data come from 1999.

${ }^{8}$ The base dataset, from The Warren Group, contained 798,202 observations, and so I have been able to retain $78 \%$ of the original observations.
} 
and Gayer, 2009). A recent literature in environmental economics has sprung up to adapt quasi-experimental approaches from other fields of economics to environmental issues in order to deal with these issues. ${ }^{9}$

There are three broad classes of quasi-experimental approaches: Differences-in-Differences or Fixed-effects, Instrumental Variables, and Regression Discontinuity (Greenstone and Gayer (2009), Parmeter and Pope (2009)). In this paper I apply the first of these, the Differences-in-Differences approach. This approach takes advantage of the 'panel' nature of my dataset to help solve both the omitted variables and selection bias problems identified above. ${ }^{10}$ By including census block, census block-group, or even property-level fixed effects, I am able to control for any constant but unobserved factors that act at the local level and may be correlated both with property values and the explanatory variables of interest, and thus greatly reduce the chance of substantial remaining omitted variables or selection bias. Suppose for instance that towns with higher average incomes are more likely to pass the CPA. In the absence of fixed effects, I would observe a spurious positive correlation between passage of the CPA and property values. However, by including the fixed effects, and since town relative average incomes are likely to be reasonably constant over the sample period, I am now controlling for this, and any other, static factors. Essentially, my regression coefficients will be the average within-group (census block, block-group, or property) impact of each explanatory variable.

One downside to this approach is that successful estimation will require sufficient withingroup variation in each explanatory variable. Obviously, the smaller the groups the more factors that are being controlled for in the fixed-effect, but also the less variation that will be observed and the less statistical power I will have. The reason for this is that other included static covariates, such as distance to active rail lines, are being measured within the fixed effects group, so that I am measuring the effects of very small changes in these distance variables since variation in distance within a census block or block group is, by

\footnotetext{
${ }^{9}$ See, for example, Parmeter and Pope (2009), Greenstone and Gayer (2009), and Klaiber and Smith (2009). For an excellent survey of general program evaluation methods, see Imbens and Wooldridge (2009).

${ }^{10}$ This is akin to the approach taken by Deschênes and Greenstone (2007) in a study of the property-value effects of weather and climate on agricultural land.
} 
definition, quite small. ${ }^{11}$ I test the robustness of my results to changing the scale of the fixed-effect, and will look to balance these competing interests in determining the optimal scale.

What remains as potential confounding factors in this analysis - in particular the estimation of the treatment effect - are factors that are not constant over time. If any of these factors are changing co-incident with both property values and the passage of the CPA in a community, then I could be mis-attributing changes in property values to the CPA. This would be of particular concern if I had only a small sample of communities being treated. With my large sample, while these types of factors may be affecting individual communities, for me to mistake some other effect for that of the CPA it would have to be happening consistently in most of the 140 treatment communities at the same time as CPA passage, which varies considerably amongst the treatment communities, and this seems unlikely. To help with this matter, however, I do include a number of time-dependent controls. To net out any macro-level trends, I include year dummy variables. I also include month dummies to account for seasonal effects. Finally, I normalize sales prices according the the Federal Housing Finance Agency's (FHFA) House Price Index. This is calculated at the U.S. Census MSA level, which, in Massachusetts, are counties or groups of counties. Together, these three adjustments de-trend and de-seasonalize the data, and allow me to isolate town-level effects, like the CPA.

In conducting a hedonic property-value analysis one must also be alert to spatial dependence and spatial auto-correlation. ${ }^{12}$ A dataset exhibits spatial dependence if, in this context, property values for nearby properties are not determined independently of one another. That is, if one property's value depends on the value of its neighbor's. Spatial auto-correlation, similarly, is when the error terms for neighboring or nearby properties are not independent of one another. Both of these concerns can be expected in hedonic property-value models. A fully general spatial econometric estimation approach would assume a spatial weighting matrix that would, for any pair of properties describe how 'close'

\footnotetext{
${ }^{11}$ It is also true that the fixed effects do not completely eliminate possible omitted variables bias for these variables, although it does greatly reduce the scope for this potential problem.

${ }^{12}$ See LeSage and Pace (2009) for a complete treatment of this subject.
} 
they are to each other, and, assuming that this matrix is correctly specified, one can control for both spatial dependence and spatial autocorrelation. Given the size of my dataset, however, so general an approach is extremely computationally intensive. Conveniently, however, there are some simpler ways to control for spatial issues. First, spatial dependence can be partially controlled for by the local-area fixed effects. In effect, this approach allows for spatial dependence within groups, but not across groups. Secondly, spatial autocorrelation can be controlled for in a similar manner by allowing for error clustering within defined groups (not necessarily at the same spatial level at the fixed-effects groups), which simultaneously makes the calculated error terms robust to heteroskedasticity. ${ }^{13}$

Following Bertrand, Duflo, and Mullainathan (2004) and Parmeter and Pope (2009), the form of the estimated equation can then be written:

$$
p_{i j t}=\lambda_{t}+\alpha_{j}+z_{j t} \beta+x_{i j t} \delta_{j t}+\eta_{j t}+\epsilon_{i j t}
$$

where $p_{i j t}$ represents the price of property $i$ in group $j$ at time $t ; \lambda_{t}$ represents the set of time dummy variables; $\alpha_{j}$ represents the group fixed effects; $z_{j t}$ represents the treatment variable; $x_{i j t}$ represents the set of other explanatory variables; and $\eta_{j t}$ and $\epsilon_{i j t}$ represent group and individual-level error terms respectively.

Another issue in any analysis of land-use issues values is the proper measurement of land-use. Perhaps the most frequent measure is the distance to the nearest parcel of a certain type. While this measure has clear merits I do not believe it is the whole story. Instead, I measure the total acreage of parcels of each type that intersect a buffer around the transacted properties. ${ }^{14}$ This, I believe gives a more complete picture of possible impacts. Figure 3 provides an example of this measure. An implicit tradeoff exists in expanding the size of the buffer used to measure these land-uses. Larger buffers provide for a more complete measure of the effects of land-uses on property values. However, larger buffers also imply less variation in the land-use variables, reducing the power of the estimation,

\footnotetext{
${ }^{13}$ Essentially, combined, these fixes allow for spatial weighting matrices containing ' 1 's for all observations within groups and zeros elsewhere.

${ }^{14} \mathrm{I}$ do not have information on parcel boundaries, so instead use point estimates of each home's latitude/longitude provided by The Warren Group.
} 


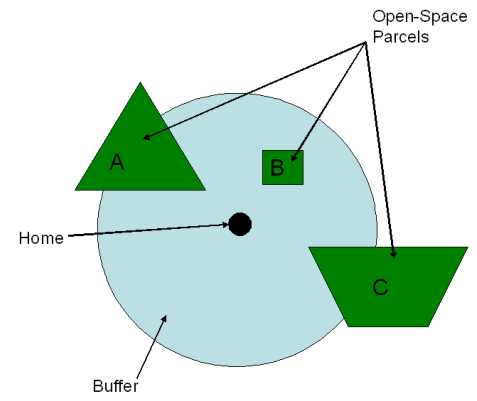

Figure 3: Example of Land-Use Measures

and also become very computationally expensive. Given the substantial correlation in my measure of land-use between various buffers, I restrict my measures to buffer radii of 0.1 miles and 0.25 miles. ${ }^{15} \mathrm{I}$ do employ a distance measure for other factors such as the distance to highways, highway exits, active rail lines, and passenger rail stations.

\footnotetext{
${ }^{15}$ Admittedly, it would be nice to have more flexibility in buffer sizes. However, given the size of my dataset, it is very computationally intensive to calculate the land-use variables for a given buffer, and this intensity increases with the size of the buffer. So, these two buffers were chosen in an ad hoc fashion, and I am unable to explore fully the effects of these choices.
} 


\section{Results}

I begin by regressing the log of the normalized sales price on the full range of possible explanatory variables, including home characteristics, local land-use characteristics measured with a 0.1 mile buffer, the zone in which the home is located, a series of other locational variables, the monthly unemployment rate, and, finally, the CPA status in the town in which the home is located on the date of the sale. ${ }^{16}$ That is, the CPA dummy equals one only in town-months in which the CPA has been passed, and equals zero elsewhere. So, it is always zero in towns that never pass the CPA, as well as in towns that pass the CPA, before they pass it. Table 1 provides summary statistics for the variables included in this analysis. I include two primary measures of CPA status - a simple dummy variable for whether or not the CPA had passed in that community prior to the sale date and secondly, the effective surcharge rate passed in the community, which is zero for those towns that had not yet enacted the CPA. As mentioned above, I also vary the geographic scale of the fixed effects to test the robustness of the estimates to this important assumption. Table 2 provides the results of these regressions.

\footnotetext{
${ }^{16}$ The semi-log specification is chosen to allow for better comparisons to other literature in this area, specifically, Cropper, Deck, and McConnell (1988).
} 
Table 1: Summary Statistics

\begin{tabular}{|c|c|c|c|}
\hline Variable & Definition & Mean & Std. Dev. \\
\hline monthurate & Monthly Town-Level Unemployment Rate & 4.539716 & 1.655781 \\
\hline rddistance & Distance to Highway & 0.006755 & 0.013825 \\
\hline exitsdist & Distance to Highway Exit & 0.044549 & 0.049956 \\
\hline trnarcdist & Distance to Active Rail Line & 0.015873 & 0.018856 \\
\hline trnnoddist & Distance to Passenger Rail Station & 0.054687 & 0.065783 \\
\hline lotsizesf & Lot Size (Square Feet) & 22746.07 & 97456.32 \\
\hline grbldgarea & Interior Building Area (Square Feet) & 2224.684 & 2764.99 \\
\hline bedrooms & Bedrooms & 2.738458 & 1.243927 \\
\hline bathrooms & Bathrooms & 1.524233 & 0.852707 \\
\hline halfbaths & Halfbaths & 0.474044 & 0.568962 \\
\hline cropland & Cropland (Acres) & 2.566178 & 30.74757 \\
\hline pasture & Pasture (Acres) & 0.395627 & 3.215353 \\
\hline forest & Forest (Acres) & 729.9053 & 2406.253 \\
\hline freshwetland & Freshwater Wetlands (Acres) & 1.164864 & 10.98079 \\
\hline mining & Open Pit Mining (Acres) & 0.106971 & 2.477815 \\
\hline open & Vacant Open Land (Abandoned/Non-Vegetated, Acres) & 5.666941 & 168.714 \\
\hline multires & Multi-Family Residential (Acres) & 33.58175 & 216.771 \\
\hline highdensres & High-Density Residential (Lots less than $1 / 4$ Acre, Acres) & 181.0062 & 451.5845 \\
\hline meddensres & Medium Density Residential (Lots $1 / 4$ to $1 / 2$ Acre, Acres) & 108.7597 & 262.7586 \\
\hline lowdensres & Low Density Residential (Lots more than $1 / 2$ Acre, Acres) & 17.32016 & 86.9929 \\
\hline saltwetland & Saltwater Wetland (Acres) & 1.605651 & 32.49791 \\
\hline commercial & Commercial Land (Acres) & 13.47407 & 53.30502 \\
\hline industrial & Industrial Land (Acres) & 2.3377 & 14.32137 \\
\hline urbanopen & Urban Open Space (Parks, Acres) & 3.843223 & 23.92888 \\
\hline transporta $\mathrm{n}$ & Transportation (Roads, Highways, Rail Corridors/Stations, Parking, Acres) & 16.7739 & 87.48042 \\
\hline waste & Waste Facilities (Acres) & 0.043256 & 0.821047 \\
\hline freshwater & Freshwater/Coastal Embayments (Acres) & 6.736147 & 52.85323 \\
\hline forestag & Forested Agriculture (Orchards, Acres) & 0.380751 & 6.11992 \\
\hline age & Age of Home (Years) & 74.38416 & 227.0078 \\
\hline Condominium & Condominium & 0.301492 & 0.458906 \\
\hline CapeCod & Cape Cod Style Home & 0.116604 & 0.320948 \\
\hline Ranch & Ranch-Style Home & 0.141441 & 0.348476 \\
\hline Townhouse & Townhouse & 0.042015 & 0.200623 \\
\hline Colonial & Colonial Home & 0.191235 & 0.393274 \\
\hline Contemporary & Contemporary Home & 0.020652 & 0.142218 \\
\hline Apartment & Apartment-Style Condominium & 0.141835 & 0.348881 \\
\hline zonecom & Zoned Commercial & 0.06622 & 0.248667 \\
\hline zoneind & Zoned Industrial & 0.023409 & 0.151199 \\
\hline zonecons & Zone Conservation & 0.006045 & 0.077517 \\
\hline zonelowres & Zoned Low-Density Residential & 0.037022 & 0.188816 \\
\hline zonelowmed s & Zoned Low-Medium Density Residential & 0.193629 & 0.395142 \\
\hline zonemedres & Zoned Medium Density Residential & 0.161949 & 0.368404 \\
\hline zonemedhig s & Zoned Medium-High Density Residential & 0.074448 & 0.262499 \\
\hline zonehighres & Zoned High Density Residential & 0.263548 & 0.440558 \\
\hline zoneagres & Zoned Agriculture/Residential & 0.036277 & 0.186979 \\
\hline zonemulti & Zoned Multiple-Uses & 0.114448 & 0.318355 \\
\hline
\end{tabular}




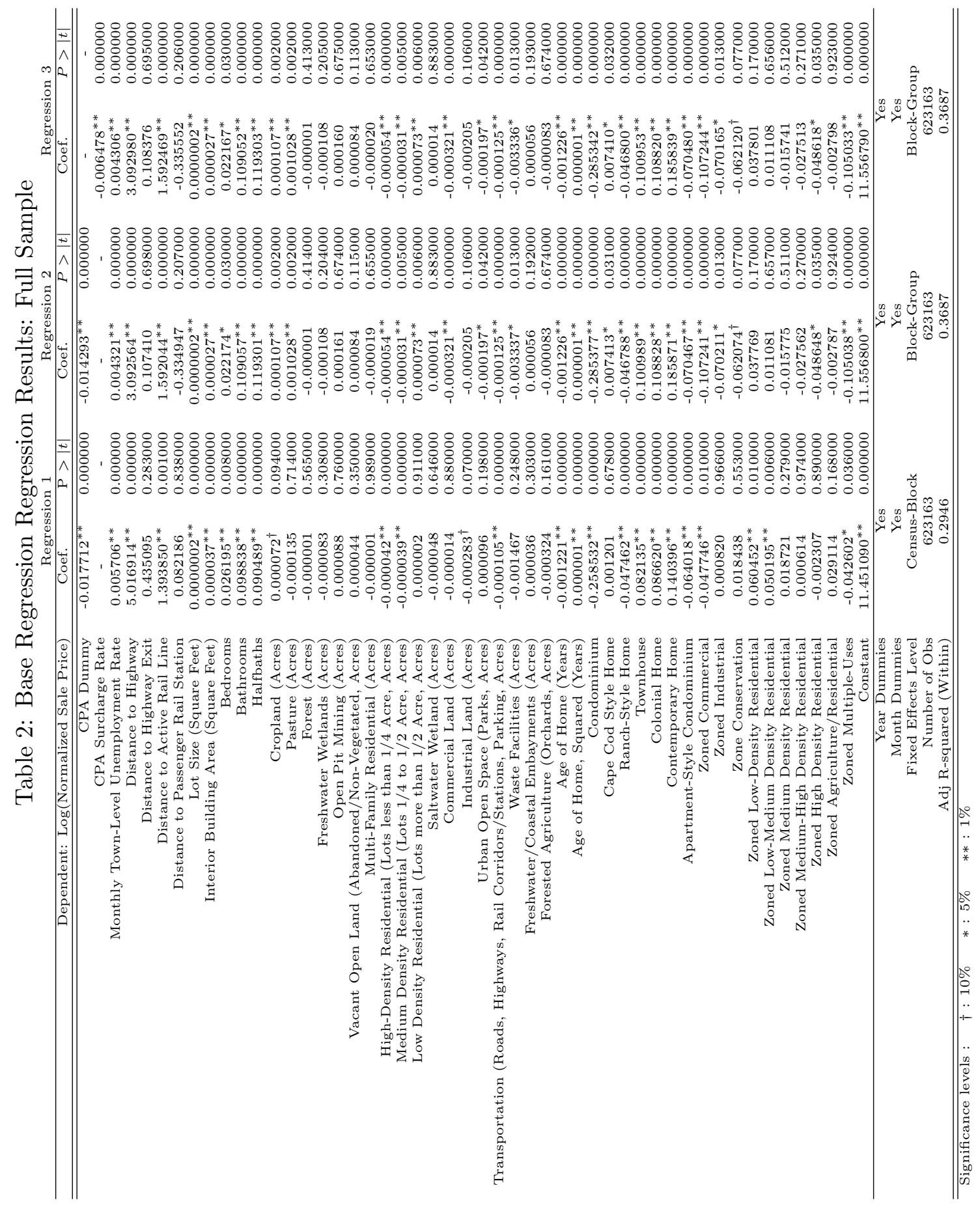


Regressions 1 and 2 include the CPA dummy, while Regression 3 uses the surcharge rate. Regression 1 uses census block fixed effects, while Regressions 2 and 3 use census blockgroup fixed effects. I will focus mostly on Regressions 2 and 3 in the discussion below. This is because the results at this broader geographic scale of fixed effects are generally more significant. This is intuitive, and consistent with Kuminoff, Parmeter, and Pope (2009). As we increase the scale of the fixed-effect, we perhaps open ourselves up to more omitted variables, but simultaneously allow for more variation in the included covariates which gives our estimates more power. At the block-group level, however, we still have 4,991 groups, each averaging only 125 observations.

The CPA dummy coefficient gives the percentage change in price for a binary change to the value of the dummy variable. This indicates that passage of the CPA results in a $1.43 \%$ to $1.77 \%$ reduction in home prices. Similarly the surcharge rate coefficient gives the percentage change in price for a unit increase in the surcharge rate, and implies a $0.65 \%$ reduction. These results are broadly consistent with each other since most towns choose a $3 \%$ surcharge.

Strangely, the monthly unemployment rate is positively related to home prices. This result is robust to changing the specification of the property value/unemployment rate relationship. This must reflect some omitted variable that is causing a spurious correlation. Thankfully, however, omitting the unemployment rate from the analysis does not change the estimate of the CPA coeffcient, which indicates that whatever is driving this result, it is not affecting our estimate of the CPA effect.

The distance variables suggest, as we would expect, that people will pay a premium for increased distance from highways and active rail lines. The estimates for exits and stations, included in an attempt to separate convenience aspects of transportation from the associated dis-amenities are not significant, although when using the block-group fixed effects, the station variable is of the right sign. All of the home characteristic variables are positive and significant with the exception of age, which is negative, but decreasing at a decreasing rate. Condominiums are cheaper than single-family homes and relative to an excluded 'other-style' category, Colonials and Contemporaries are more expensive while 
ranches and flats are less expensive.

The type of 'zone' a home is in also affects its value. Relative to an excluded 'other' category, commercial, industrial, high-density residential, and conservation zoning, not surprisingly, generally have negative impacts on home prices, while most other residential categories are positive or insignificant. The conservation zoning result is perhaps most interesting. It suggests that the limitations inherent with such zoning policies are harming property values, and this may help explain the negative impact of the CPA - if passage of the CPA implies that a significant sample of homes will be subject to increased restrictions on development, this may reduce average prices. 


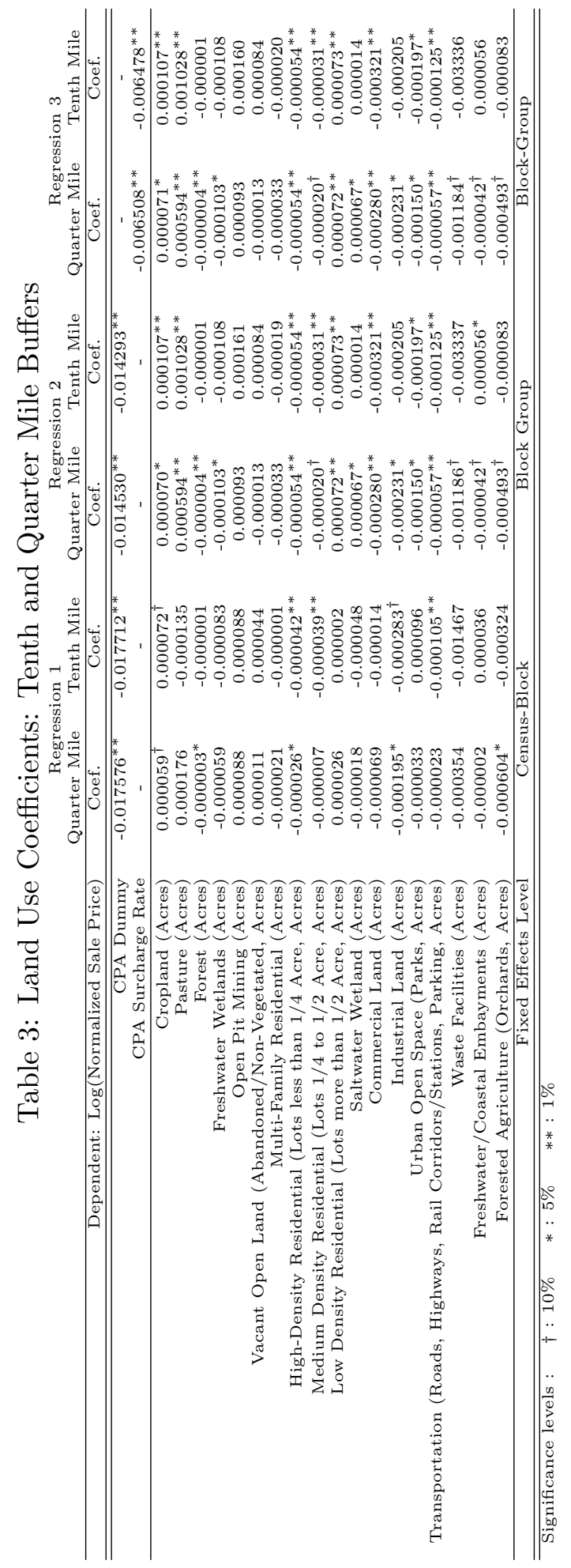


Finally, many of the land-use coefficients are significant. Cropland, pasture, and lowdensity residential land-uses are positively related to home prices. High and medium density residential development, as well as commercial, urban open space, transportation, and waste land-uses are negatively related to home prices. Industrial development is also negatively related, but it is not quite significant at the $90 \%$ level. All of these results are to be expected, except, perhaps for the urban open space result. Congestion effects associated with use of these parks may be driving this result. The results presented also highlight the effect of changing the geographic level of the fixed effect. When fixed effects are calculated at the census block level, the lack of variation within blocks seems, indeed, to lead to insignificant estimates of the land-use effects, but this is reversed when expanding the fixed-effects to the census block-group level. ${ }^{17}$ These results are robust to increasing the buffer size to 0.25 miles. Table 3 compares the coefficients for the land-use variables in each of the three base regressions described above for the 0.1 mile and 0.25 mile buffers. Estimates are remarkably consistent between the two buffers, and, in most cases, coefficient levels are lower in absolute value at the quarter-mile buffer than at the tenth-mile buffer which suggests that homeowners care more about land uses closer to their home. Note also, the consistency in estimates of the referendum effect. ${ }^{18}$ Table 4 reports some results from a regression including land-use variables for the 0.1 mile buffer together with the acres of each land use that intersect the 0.25 mile buffer but not the 0.1 mile buffer. These results are all consistent with the results reported above.

\footnotetext{
${ }^{17}$ There are 69,320 census blocks represented in my dataset, with an average of only 9 observations per block. There are only 4,991 census block groups represented in the dataset, with an average of about 125 observations per block-group.

${ }^{18}$ As a whole, the set of other variables included are left largely unchanged by the change in buffer.
} 


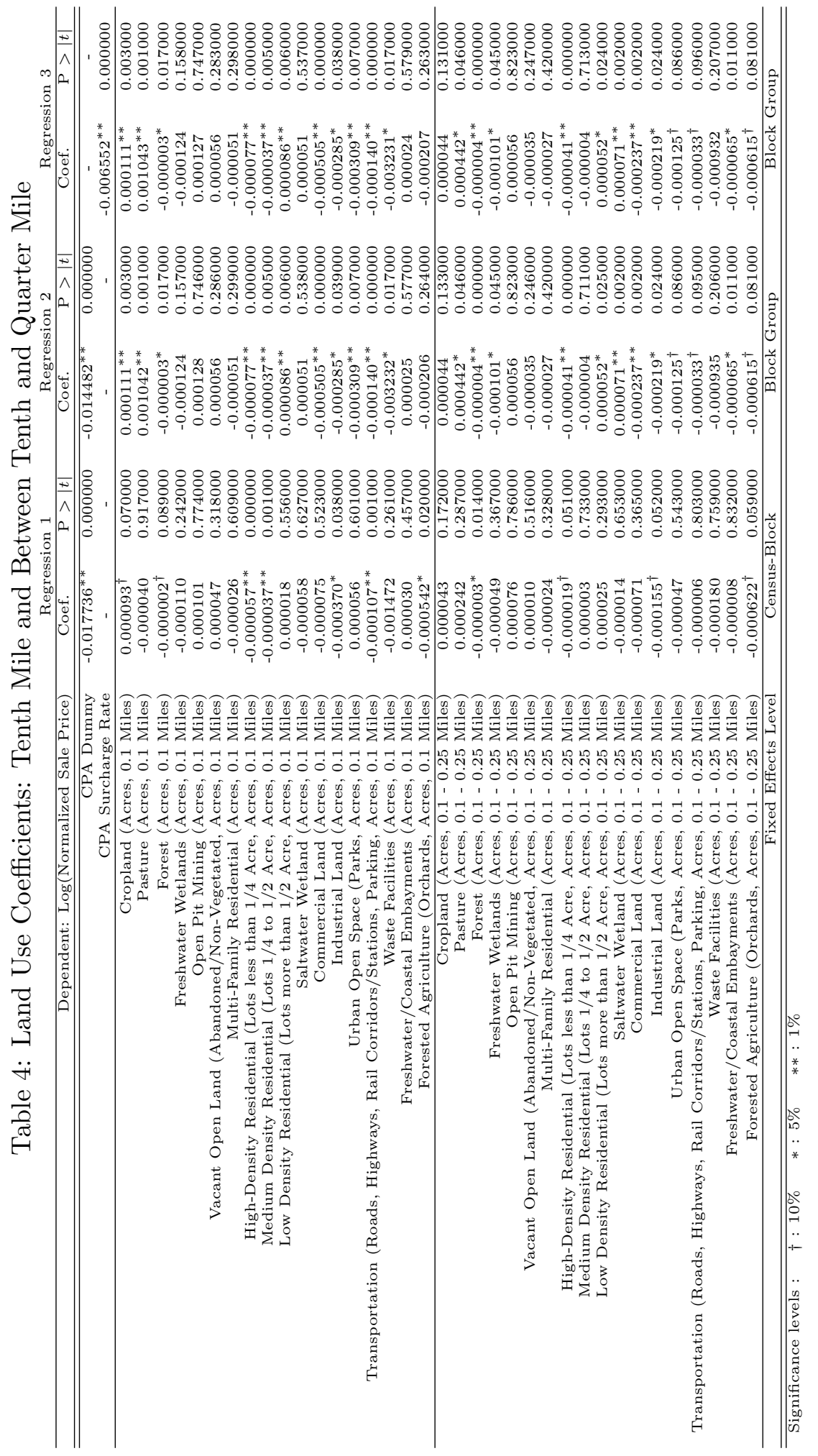


Table 5: Base Regression Regression Results: Repeat Sample

\begin{tabular}{rcc}
\hline Dependent: Log(Normalized Sale Price) & Coef. & $\mathrm{P}>|t|$ \\
\hline \hline CPA Dummy & $-0.017790^{* *}$ & 0.000000 \\
Open Space Spending (Million\$) & 0.0022 & 0.139000 \\
Affordable Housing Spending (Million\$) & 0.0002 & 0.667000 \\
Recreation Spending (Million\$) & 0.0018 & 0.725000 \\
Historic Preservation Spending (Million\$) & $0.0051^{\dagger}$ & 0.071000 \\
Monthly Unemployment Rate & $0.007464^{* *}$ & 0.000000 \\
Constant & $11.784510^{* *}$ & 0.000000 \\
\hline Year Dummies & Yes \\
Month Dummies & Yes \\
Fixed Effects Level & Property \\
Number of Obs & 155836 \\
Adj R-squared (Within) & 0.0114 \\
\hline \hline
\end{tabular}

Significance levels : $\dagger: 10 \% \quad *: 5 \% \quad * *: 1 \%$

Given the size of my dataset and the relatively large sample period, a significant number of properties sell more than once in my sample. Limiting analysis just to these observations gives us a true fixed-effects model and greatly reduces the scope for potential omitted variables bias. This gives the cleanest possible estimate of the referendum effect, and results are presented in Table 5. The result from the full-sample analysis, that the CPA negatively impacts property values is confirmed in this analysis, and the magnitude is almost identical to that estimated above. This analysis also includes variables representing the running sum of reported CPA expenditures in each of four areas: open-space, affordable housing, recreation, and historic preservation. All seem to be positively related to property values, but only historic preservation spending is significant. An alternative specification, which included the share of each category as a percentage of total reported spending, gave no statistically significant results. 


\section{Discussion}

The regression coefficients described above indicate a negative and significant impact of CPA passage on property values of about $1.5 \%$, on average. It is straightforward to put this number in perspective. For the average home, this reduction amounts to a reduction in price of about $\$ 1,991$. On the other hand, the average increase in taxation from the CPA is about $\$ 112$ per year. The present value cost of this additional tax, at a $5 \%$ interest rate is $\$ 2,352$ and so the tax is being capitalized into property values at a rate of about $85 \%$. This rate of tax capitalization is somewhere between the consensus estimates from the tax capitalization literature by Palmon and Smith (1998) and Oates (1966) of between $56 \%$ and $66 \%$ and that predicted by Ricardian equivalence $-100 \%$.

As with any regression coefficient, however, this estimate of the referendum effect is simply an average effect across the sample. To see the extent of variation away from this estimate, I interact the CPA dummy with county dummies and with the land-use measures. Table 6 provides the estimates of the interaction terms from this regression. 19 There are significant negative impacts of the CPA in two counties, Middlesex and Norfolk, and significant positive effects in Hampshire, Nantucket, and Plymouth counties. The point estimates range from a $3.7 \%$ decline in values in Middlesex County to a $4.7 \%$ increase in values in Plymouth County. The large negative impacts in Middlesex and Norfolk counties may be helping to drive the overall negative average effect of the CPA since Middlesex and Norfolk are two of the three largest counties in terms of number of observations. This result does not have an obvious explanation, although a possible explanation for the Middlesex result is that a very large share, some $31 \%$, of existing CPA spending has been on affordable housing, the second-highest in the sample. The Land-Use interaction results are also very interesting. We see that high-density residential and industrial land have positive impacts on the CPA effect, while low-density residential land has a negative impact on the CPA effect. This suggests that those homes in more densely developed areas stand to benefit more from the CPA than those in less densely developed areas, which is consistent with

\footnotetext{
${ }^{19}$ The estimates for the other variables, the same as those in Table 2 are very similar to those in the base regression.
} 
Table 6: County and Land-Use Interaction Results

\begin{tabular}{|c|c|c|c|}
\hline Interaction Term (*Referendum) & Coefficient & t-stat & $\mathrm{P}>|t|$ \\
\hline Barnstable (Baseline) & -0.0058474 & -0.64 & 0.519 \\
\hline Berkshire & 0.0239911 & 0.67 & 0.501 \\
\hline Bristol & 0.0187450 & 1.14 & 0.252 \\
\hline Dukes & 0.0123199 & 0.35 & 0.725 \\
\hline Essex & -0.0134161 & -0.9 & 0.369 \\
\hline Franklin & -0.0092139 & -0.23 & 0.818 \\
\hline Hampden & -0.0171248 & -1.46 & 0.144 \\
\hline Hampshire & $0.0251612^{\dagger}$ & 1.71 & 0.087 \\
\hline Middlesex & $-0.0377506^{* *}$ & -3.2 & 0.001 \\
\hline Nantucket & $0.1106750^{*}$ & 2.11 & 0.035 \\
\hline Norfolk & $-0.0295369^{* *}$ & -2.67 & 0.008 \\
\hline Plymouth & $0.0476539^{* *}$ & 3.79 & 0 \\
\hline Worcester & -0.0165742 & -1.03 & 0.305 \\
\hline Cropland & 0.0000005 & 0.01 & 0.993 \\
\hline Pasture & 0.0005590 & 0.82 & 0.413 \\
\hline Forest & -0.0000005 & -0.29 & 0.772 \\
\hline Freshwater Wetlands & -0.0001827 & -0.84 & 0.4 \\
\hline Open Pit Mining & 0.0002478 & 0.64 & 0.523 \\
\hline Vacant Open Land & -0.0000907 & -1.52 & 0.13 \\
\hline Multi-Family Residential & 0.0000231 & 0.44 & 0.659 \\
\hline High-Density Residential & $0.0000232^{*}$ & 2.54 & 0.011 \\
\hline Medium Density Residential & -0.0000083 & -0.58 & 0.561 \\
\hline Low Density Residential & $-0.0000809^{* *}$ & -5.31 & 0 \\
\hline Saltwater Wetland & 0.0001514 & 1.62 & 0.105 \\
\hline Commercial Land & 0.0002659 & 1.41 & 0.158 \\
\hline Industrial Land & $0.0002948^{\dagger}$ & 1.79 & 0.073 \\
\hline Urban Open Space & -0.0003786 & -1.32 & 0.188 \\
\hline Transportation & -0.0000240 & -0.42 & 0.672 \\
\hline Waste Facilities & -0.0041133 & -1.16 & 0.247 \\
\hline Freshwater/Coastal Embayments & 0.0000708 & 0.77 & 0.444 \\
\hline Forested Agriculture & -0.0000144 & -0.05 & 0.959 \\
\hline
\end{tabular}

intuition since open-space is presumably more scarce in more densely developed areas. More generally, this observed heterogeneity in impact is consistent with prior literature (Heintzelman (2010), Geoghegan (2003), Anderson and West (2006)), which has found the same sorts of heterogeneity in estimating the value of open space preservation.

Similar to the true fixed-effects analysis including only repeat-sales, I tried including data on spending in the full-sample regressions. I attempt a number of specifications, and very few of them yield any significant results. One result that is consistent across specifications, however, is that total spending is negative and significant while its square is positive and significant. When these terms are included, the magnitude of the estimate for the effect of 
the CPA is reduced, although it is still significant and negative. This suggests that larger programs have larger negative effects, which is consistent with the result from estimating the effect of the rate rather than just the CPA dummy. If I leave out the total spending variables and instead include only categorical spending variables rather than categorical shares, expenditures on Open Space, Affordable Housing and Recreation have negative impacts, although only that for Affordable Housing is significant, while expenditures on Historic Preservation are positive, but insignificant. This gives some evidence that, of the four categories, affordable housing is the least preferred and most likely to decrease property values.

Moving to the measures of land-use, it is interesting to discuss these results with the aid of a simple heuristic - what is the effect on sales price if 1 acre of land near a home changes from an open space category to a developed category. Table 7 presents the results of asking this question for the median home in the state-wide sample. ${ }^{20}$ Notice, as an example, that replacing an acre of pasture with an acre of commercial development would reduce price by almost $\$ 180$. Of course, most commercial developments are at a considerably larger scale, implying much larger price effects. The most preferred land-uses, which are also statistically significant, are Pasture and Cropland, implying, perhaps, that something about farmland makes it preferable to other low-density uses. Even conversion to low-density residential development would lower neighboring home prices.

\footnotetext{
${ }^{20}$ Only changes in prices from increases in acreage are presented. The results for decreases are, obviously, almost identical and are thus omitted for simplicity.
} 


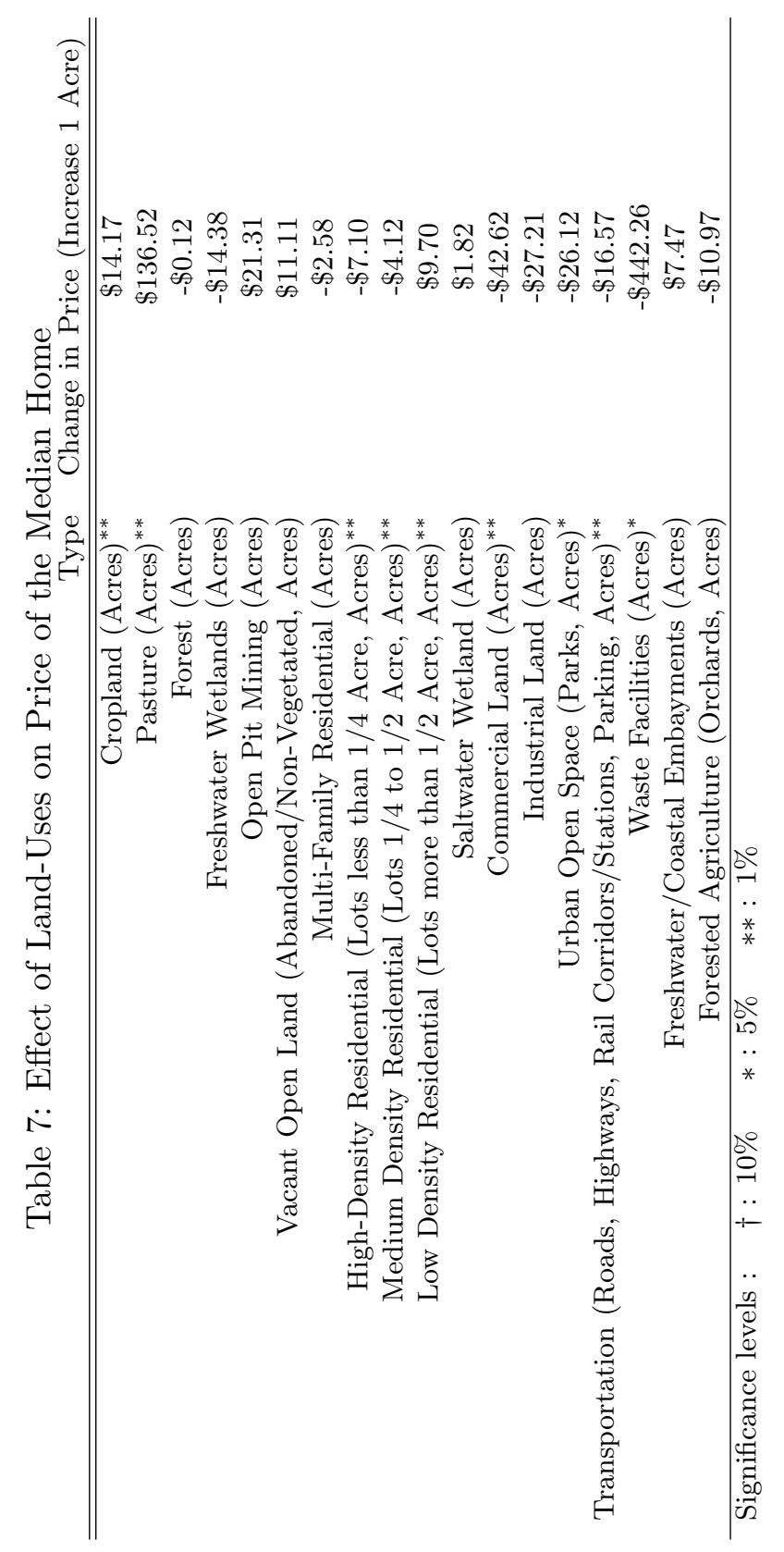




\section{Conclusions}

This paper provides evidence that preservation policies, while generally providing public goods, and even when approved through a voter-referendum, may not be positively capitalized into home values. Using the quasi-experimental method of differences-in-differences analysis, I find that, in the case of the Massachusetts Community Preservation Act, passage of the $\mathrm{CPA}$ has had an overall negative impact on property values of about $1.5 \%$ in towns that pass the CPA. This effect is observed to be heterogeneous across counties and according to local land-use characteristics, with more densely developed areas seeing more benefits than those less densely developed. Nonetheless, the land-uses that are at least partially being targeted for preservation under the CPA do appear to have value for homeowners, relative to more developed uses. While it remains somewhat of a puzzle why towns would pass policies that are negatively affecting property values, it can explain why, in many towns, passage of the CPA is controversial, and why more than half the towns in Massachusetts still have not adopted the policy. ${ }^{21}$ I present some evidence that spending on Community Housing helps to drive down the impact of the CPA, which is consistent with intuition, but more work needs to be done to fully establish that point.

\footnotetext{
${ }^{21}$ Of the 140 communities that passed the CPA before 2008, the median margin was $58 \%$ to $42 \%$. In addition, 58 towns rejected the measure, and another 151 towns have not put it to a vote.
} 


\section{References}

[1] Soren T. Anderson and Sarah E. West. Open space, residential property values, and spatial context. Regional Science and Urban Economics, 36:773-789, 2006.

[2] Marianne Bertrand, Esther Duflo, and Sendhil Mullainathan. How much should we trust differences-in-differences estimates? Quarterly Journal of Economics, 119:249275, February 2004.

[3] Jan K. Brueckner. A test for allocative efficiency in the local public sector. Journal of Public Economics, 19:311-331, 1982.

[4] Maureen L. Cropper, Leland B. Deck, and Kenneth E. McConnell. On the choice of functional form for hedonic price functions. Review of Economics and Statistics, 70(4):668-675, 1988.

[5] Olivier Deschênes and Michael Greenstone. The economic impacts of climate change: Evidence from agricultural output and random fluctuations in weather. American Economic Review, 97(1):354-385, March 2007.

[6] Jacqueline Geoghegan, Lori Lynch, and Shawn Bucholtz. Capitalization of open spaces into housing values and the residential property tax revenue impacts of agricultural easement programs. Agricultural and Resource Economics Review, 32(1):33-45, 2003.

[7] Michael Greenstone and Ted Gayer. Quasi-experiments and experimental approaches to environmental economics. Journal of Environmental Economics and Management, $57: 21-44,2009$.

[8] Martin D. Heintzelman. Measuring the property-value effects of local land use and preservation referenda. Land Economics, 86(1), February 2010. Forthcoming.

[9] Guido W. Imbens and Jeffrey M. Wooldridge. Recent developments in the econometrics of program evaluation. Journal of Economic Literature, 47(1):5-86, March 2009. 
[10] H. Allen Klaiber and V. Kerry Smith. Evaluating rubin's causal model for measuring the capitalization of environmental amenities. NBER Working Paper 14957, National Bureau of Economic Research, May 2009.

[11] Matthew J. Kotchen and Shawn M. Powers. Explaining the appearance and success of voter referenda for open-space conservation. Journal of Environmental Economics and Management, 52:373-390, July 2006.

[12] Nicolai V. Kuminoff. Using a bundled amenity model to estimate the value of cropland open space and determine an optimal buffer zone. Unpublished Working Paper, July 2008.

[13] Nicolai V. Kuminoff, Christopher F. Parmeter, and Jaren C. Pope. Specification of hedonic price functions: Guidance for cross-sectional and panel data applications. Working Paper 2009-02, Department of Agriculural and Applied Economics, Virginia Polytechnic Institute and State University, Blacksburg, VA, January 2009.

[14] James P. LeSage and R. Kelley Pace. Introduction to Spatial Econometrics. Chapman and Hall, CRC Press, 2009.

[15] Virginia McConnell and Margaret Walls. The value of open space: Evidence from studies of non-market benefits. Report, Resources for the Future, January 2005.

[16] Erik Nelson, Michinori Uwasu, and Stephen Polasky. Voting on open space: What explains the appearance and support of municipal-level open space conservation referenda in the united states. Ecological Economics, 2007.

[17] Wallace E. Oates. The effects of property taxes and local public spending on property values: An empirical study of tax capitalization and the tiebout hypothesis. The Journal of Political Economy, 77(6):957-971, December 1969.

[18] Oded Palmon and Barton A. Smith. New evidence on property tax capitalization. The Journal of Political Economy, 106(5):1099-1111, October 1998. 
[19] Christopher F. Parmeter and Jaren C. Pope. Quasi-experiments and hedonic property value methods. Unpublished manuscript, Department of Agricultural and Applied Economics, Virginia Polytechnic Institute and State University, January 2009.

[20] Fabian Waltert and Felix Schläpfer. The role of landscape amenities in regional development: A survey of migration, regional economic and hedonic pricing studies. Working Paper 0710, University of Zurich, Socioeconomic Institute, August 2007. 